Wynia, A. L., V. Rolland, and J. C. Bednarz. 2021. Rat snakes, cowbirds, and vines lower passerine nest survival in remnant bottomland hardwood forests in east-central Arkansas, USA. Avian Conservation and Ecology 16(2):19. https://doi.org/10.5751/ACE-01897-160219

Copyright (C) 2021 by the author(s). Published here under license by the Resilience Alliance.

Research Paper

\title{
Rat snakes, cowbirds, and vines lower passerine nest survival in remnant bottomland hardwood forests in east-central Arkansas, USA
}

\author{
Amy L. Wynia ${ }^{1}$, Virginie Rolland ${ }^{1}$ and James C. Bednarz ${ }^{2}$ \\ ${ }^{1}$ Arkansas State University, ${ }^{2}$ University of North Texas
}

\begin{abstract}
Predation is often the leading cause of nest failure among passerines; however, specific causes are often unknown or can be misidentified in the field. Therefore, it is critical to improve our understanding of causes of nest predation and factors that influence passerine nest success. In the remnant bottomland hardwood forests of east-central Arkansas, we monitored 282 passerine nests during summers 2010-2012, including 81 nests at which we deployed video cameras. We calculated daily survival rates (DSRs) across species, locations, and years and determined which temporal, biological, and habitat variables correlated with nest success. We also estimated predation rates by specific predator groups. Our largest sample-sized species, Indigo Buntings (Passerina cyanea, $\mathrm{n}=143 \mathrm{nests)}$ and Northern Cardinals (Cardinalis cardinalis, $\mathrm{n}=97$ nests), had similar mean DSRs $(0.932 \pm 0.01,0.924 \pm 0.01$, respectively). Predation by all species and parasitism by Brown-headed Cowbirds (Molothrus ater) together were the most frequent causes of nest failures ( $29 \%$ and 33\%, respectively), although black rat snake (Pantherophis obsoletus) was the most frequent predator (37\% of known predation events). Nest stage and number of vine tents best explained variation in DSRs; however, predictors of predation rates varied across predator groups. For example, vegetation density negatively influenced the probability of nest predation by snakes and mammals, but positively influenced the probability of nest predation by cowbirds and did not influence the probability of nest predation by other avian predators. Using camera systems can help elucidate nest fate patterns and predation trends across species and highlight factors such as time of predation, accurate nestling age, and interspecific interactions. Importantly, our predator-specific results suggest managers should consider techniques suitable for the suite of passerines and predators in their local ecosystems to alleviate high predation pressure, facilitate successful reproduction, and ultimately, population persistence.
\end{abstract}

\section{Les serpents ratiers, les vachers à tête brune et les lianes réduisent la survie des nids de passereaux dans les dernières forêts feuillues des basses terres de l'est et du centre de l'Arkansas}

RÉSUMÉ. La prédation est souvent la cause principale de l'échec des nids de passereaux ; toutefois, les causes exactes sont parfois inconnues ou peuvent être mal identifiées sur le terrain. En conséquence, il est essentiel d'améliorer notre compréhension des causes de la prédation des nids et les facteurs qui influencent le succès des nids de passereaux. Dans les dernières forêts feuillues des basses terres de l'est et du centre de l'Arkansas, nous avons observé 282 nids de passereaux pendant l'été de 2010 à 2012 , dont 81 nids sur lesquels nous avons déployé des caméras vidéo. Nous avons calculé les taux de survie quotidiens (TSQ) selon les espèces, les sites et les années et avons identifié les variables temporelles, biologiques et d'habitat qui sont corrélées au succès des nids. Nous avons également estimé les taux de prédation en fonction de groupes spécifiques de prédateurs. Les espèces pour lesquelles nous disposions des échantillons les plus importants, le passerin indigo (Passerina cyanea, $\mathrm{n}=143$ nids) et le cardinal rouge (Cardinalis cardinalis, $\mathrm{n}=97$ nids), présentaient un TSQ moyen similaire $(0,932 \pm 0,01,0,924 \pm 0,01$, respectivement). La prédation par toutes les espèces et le parasitisme par les vachers à tête brune (Molothrus ater) réunis étaient les causes les plus fréquentes de l'échec des nids ( $29 \%$ et $33 \%$ respectivement), même si le serpent ratier noir (Pantherophis obsoletus) était le prédateur le plus répandu (37\% des événements de prédation connus). L'emplacement des nids et le nombre d'enchevêtrements de lianes sont les éléments qui expliquent le mieux les variations de TSQ ; toutefois, les indicateurs de taux de prédation variaient selon les groupes de prédateurs. Par exemple, la densité de la végétation affectait de manière négative la probabilité de prédation des nids par des serpents et des mammifères, mais influait de manière positive sur la probabilité de prédation des nids par les vachers à tête brune, tout en restant sans effet sur la probabilité de prédation des nids par d'autres oiseaux prédateurs. L'utilisation de caméras peut contribuer à élucider les modèles de sort des nids et les tendances de prédation selon les espèces et mettre en évidence des facteurs tels que l'heure de prédation, l'âge exact des oisillons et les interactions entre les espèces. Plus important, nos résultats spécifiques aux prédateurs suggèrent que les responsables devraient envisager des techniques adaptées à la surveillance des passereaux et des prédateurs dans leurs écosystèmes locaux afin d'alléger la pression liée à la forte prédation et de faciliter la reproduction et finalement, la survie de la population.

Key Words: Cowbird parasitism; daily survival rates (DSRs); nest predation patterns; nest-site habitat; nest success; video camera systems 


\section{INTRODUCTION}

Understanding avian nesting ecology has become critical because numerous avian species are facing population declines throughout North America (Robbins and Wilcove 1994, Northrup et al. 2019). For example, forest birds have declined by $22 \%$ since 1970 (Rosenberg et al. 2019). Potentially interacting synergistically, many factors affect avian nesting success, including severe weather (Heltzel and Earnst 2006), land-use change (Roach et al. 2018, Northrup et al. 2019), fire suppression, and predation (Ricklefs 1969).

\section{Nest predation}

Predation is often the most prevalent cause of nest failure (e.g., Newton 1998, Twedt et al. 2001, Reidy and Thompson III 2012); however, specific predators often are unknown or misidentified in the field, and partial predation and forced fledging can affect daily survival rates (DSRs) and nest productivity estimates, particularly in the late-nesting stage (Ball and Bayne 2012). Importantly, reporting inaccurate nest fate and productivity can lead to erroneous avian population trend estimates.

In recent years, video cameras have become important tools to determine nest fate, productivity, and predator species. For example, Pietz and Granfors (2000) noted 15\% of predation events would have been incorrectly identified if determined merely by evidence at the nest site. Likewise, Ball and Bayne (2012) reported $15 \%$ of nest fates were misidentified and nest productivity was overestimated by $35 \%$ by relying on field observations alone. In addition, video cameras can provide accurate information on nestling age, timing of predation events, interspecific interactions, nest defense, and avian breeding biology (Pietz et al. 2012, Wynia and Bednarz 2021).

Whether captured on video, various taxa (e.g., reptiles, birds, mammals) depredate avian nests. Snakes attack passerine nests during incubation and brooding stages (Weatherhead and BlouinDemers 2003, Stake et al. 2004, 2005). Although larger passerines may try to defend against snake attacks (Ellison and Ribic 2012), snakes often prevail and generally consume the entire contents of the nest. Occasionally, snake attacks will cause premature fledging of older nestlings (Stake et al. 2005), but often nestlings are depredated while in the nest. Feeding opportunistically on eggs and nestlings, diurnally and nocturnally, and from the ground to treetops, snakes are a formidable predator of various songbird species (Benson et al. 2010a, Chiavacci et al. 2014, Davis et al. 2019)

Avian and mammalian predators also can cause up to $76 \%$ of songbird nest failures (Pietz and Granfors 2000). Some common mammalian predators include sciurids (Liebezeit and George 2002) and mice (Peromyscus and Zapus spp.; Pietz and Granfors 2000). Among birds, common predators include raptors and corvids (Stake et al. 2004, Benson et al. 2010b, Reidy and Thompson III 2012). However, brood parasites, such as Brownheaded Cowbirds (Molothrus ater), may remove host eggs (Wood and Bollinger 1997) or consume host eggs and remove nestlings (Scott et al. 1992) before laying their own eggs (Benson et al. 2010b, Lowther 2020). Notably, not all predators use identical tactics to locate and attack nests; thus, passerines need to adapt their nesting habits and behavioral responses to predator-specific patterns in their local ecosystems.

\section{Nest-site characteristics}

Passerines select specific habitat characteristics for the placement of their nests to minimize the likelihood of predation (Reidy and Thompson III 2012), cowbird parasitism (Martin and Roper 1988), competition with ecologically similar species (Etterson et al. 2007), and to provide protection from adverse environmental conditions (Heltzel and Earnst 2006). If avoidance of predation is a primary driving selective factor, then all species using a certain microhabitat may place nests in areas with similar vegetation structure (e.g., nesting in thick cover). The total-foliage hypothesis predicts birds will nest in areas with dense vegetation; this increases nest concealment and decreases the probability of discovery by predators, including cowbirds, by enshrouding olfactory, auditory, and visual cues (Martin and Roper 1988, Martin 1992, 1993). However, not all species use foliage as a form of concealment, as cryptic plumage coloration also can provide concealment.

Alternatively, the potential-prey-site hypothesis predicts birds choose to nest in areas with several potential substrates to decrease predator search efficiency, including cowbirds (Martin and Roper 1988, Liebezeit and George 2002). These two hypotheses are not mutually exclusive. Notably, nest-site selection may not necessarily increase nest success (Chiavacci et al. 2014). Further, investigating the effects of avian nest-site selection may elucidate predator-specific patterns that may ultimately influence nest fate and productivity; these results likely have important implications for local management strategies.

Whether birds nest in areas of dense vegetation, adaptively they should choose characteristics that increase the probability of breeding success and survival. For example, parasitic attempts were fewer on Least Bell's Vireo's (Vireo belli pusillus) nests with denser vegetation $<1 \mathrm{~m}$ from the nest (Sharp and Kus 2006). However, nesting in more concealed vegetation does not always reduce predation (Holway 1991, Colwell 1992, Vergara and Simonetti 2004), suggesting additional factors affect nest success.

Passerines may not be able to select high-quality nesting habitat as habitat loss and alteration is occurring almost globally, including in North America (Stanton et al. 2018). Habitat loss notably has impacted passerines nesting in bottomland hardwood forests in the southeastern USA. This forest type has drastically decreased in size and connectivity in recent decades and has been recognized as a habitat of regional concern (Hunter et al. 1993). Since the late 1940s, 2-3 million ha of forested wetlands have been converted for agricultural purposes in the Mississippi Alluvial Valley (MAV; Twedt and Loesch 1999) and bottomland hardwood forests have been reduced to $\sim 28 \%$ of their original extent (King et al. 2005). The MAV contains approximately 50 million ha of alluvial floodplains surrounding the Mississippi River in the mid-southern USA (Chiavacci et al. 2014). Although at least $75 \%$ of bottomland hardwood forest in the MAV has been hydrologically altered and converted to agriculture, it is currently the largest contiguous remnant tract of this ecosystem type in the region (Twedt and Loesch 1999).

Of special concern are the possible cumulative pressures of brood parasitism and predation for species breeding in bottomland hardwood forests (Wilson and Cooper 1998, Benson et al. 2010a, 2010b). Although passerines from ground-nesters (e.g., Kentucky 
Warblers [Geothlypis formosa]; McDonald 2020) to canopynesters (e.g., Cerulean Warblers [Setophaga cerulea]; Buehler et al. 2020) are declining, our study focused on the understorynesting avian community, particularly open-cup nesters. Our objectives were to 1) determine specific causes of nest failure of understory-breeding passerines in bottomland hardwood forests in east-central Arkansas, 2) identify predator species, and 3) assess predator-specific patterns in relation to habitat characteristics that affect nest success. Although we focused on the total-foliage hypothesis and predicted nest survival would be higher in more concealed vegetation, we also explored the influence of other habitat variables on predator-specific patterns.

\section{METHODS}

\section{Study area}

We conducted our research at four study sites in east-central Arkansas, USA: Saint Francis National Forest $\left(34.6458^{\circ} \mathrm{N}\right.$, $\left.90.6694^{\circ} \mathrm{W}\right)$, Trusten Holder Wildlife Management Area $\left(33.9893^{\circ} \mathrm{N}, 91.3483^{\circ} \mathrm{W}\right)$, as well as Scrubgrass Bayou (34.0938 $\left.\mathrm{N}, 91.1067^{\circ} \mathrm{W}\right)$ and Rattlesnake Ridge $\left(34.2126^{\circ} \mathrm{N}, 91.1664^{\circ} \mathrm{W}\right)$, both in the White River National Wildlife Refuge (Fig. 1). Specifically, Saint Francis is composed of over 8,500 ha of bottomland and upland forests (Benson et al. 2009), the White River refuge contains $\sim 64,700$ ha of bottomland and upland forests (Chiavacci et al. 2014), and Trusten Holder comprises over 4,000 ha of bottomland hardwood forests (AGFC 2020).

Fig. 1. Study site locations where we assessed passerine nest success, causes of failure, and nest-site characteristics. Locations include Saint Francis National Forest (SFNF; $\left.34.6458^{\circ} \mathrm{N}, 90.6694^{\circ} \mathrm{W}\right)$, Trusten Holder Wildlife Management Area (THWMA; $\left.33.9893^{\circ} \mathrm{N}, 91.3483^{\circ} \mathrm{W}\right)$, as well as Rattlesnake Ridge (RSR; $\left.34.2126^{\circ} \mathrm{N}, 91.1664^{\circ} \mathrm{W}\right)$ and Scrubgrass Bayou (SGB; $34.0938^{\circ} \mathrm{N}, 91.1067^{\circ} \mathrm{W}$ ) - both located in the White River National Wildlife Refuge - in east-central Arkansas, USA, summers 2010-2012.

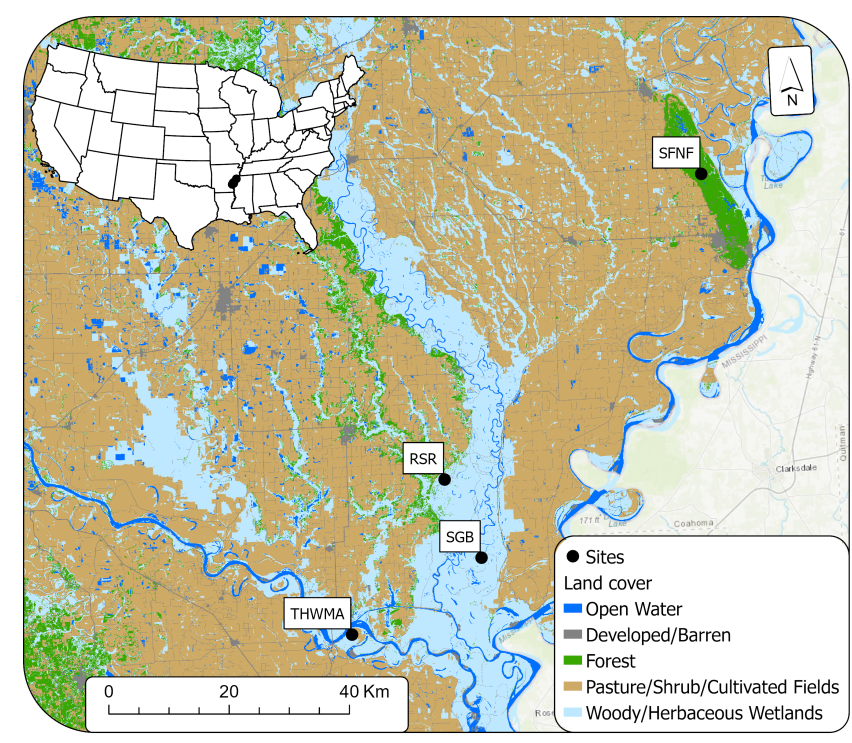

Notably, these bottomland hardwood forests occur in the largest remnant tracts within the MAV (Twedt and Loesch 1999). However, our study sites were impacted by fragmentation and edge effects through prescribed burns and timber harvests at Trusten Holder (AGFC 2020) and Saint Francis, and through timber harvests and hydrological alterations at the White River refuge (Benson et al. 2009). Further, agricultural fields surround the refuge, and a tornado damaged Trusten Holder in 2009. Therefore, both flora and fauna richness has been altered and edge effects likely will have important conservation implications.

Dominant overstory vegetation at the sites included elm (Ulmus spp.), box elder (Acer negundo), sweetgum (Liquidambar styraciflua), maple (Acer spp.), oak (Quercus spp.), hickory (Carya spp.), sugarberry (Celtis laevigata), ash (Fraxinus spp.), American sycamore (Platanus occidentalis), and tulip tree (Liriodendron tulipifera). Dominant understory vegetation included peppervine (Ampelopsis arborea), grape (Vitis spp.), greenbrier (Smilax spp.), poison ivy (Toxicodendron radicans), Virginia creeper (Parthenocissus quinquefolia), spicebush (Lindera benzoin), paw paw (Asimina triloba), and river cane (Arundinaria gigantea; Benson et al. 2010a).

\section{Nest searching and monitoring}

We conducted nest searches for all understory passerine species from early May through late July during 2010-2012. At each site, we established a $~ 72$-ha block divided into three 24-ha stands $\left(300 \times 800 \mathrm{~m}^{2}\right)$. Within each stand, 2-6 observers conducted systematic line transects every 3 days to maximize number of nests found. Observers, 3-5 m apart, repeatedly walked parallel from one end of the stand to the other while searching for nests from the ground $(0 \mathrm{~m})$ to $\sim 5 \mathrm{~m}$ in height. We followed adult passerines carrying prey and searched in areas where avian alarm calls were heard. We also searched opportunistically while engaging in other research activities, such as checking the status of nests and cameras. We recorded species, date, time, and GPS coordinates of all nests. We defined active nests by presence of eggs or nestlings, or observations of adults on nests. Empty nests were checked no less than three times at 3-day intervals (i.e., up to 9 days after initial discovery) to determine status of nests (active/ inactive). If still empty, nests were considered inactive and no longer checked.

Active nests were monitored every 3 days to determine status and fate. We recorded number of host and cowbird eggs/nestlings, presence/absence of adults, and evidence potentially related to the cause of failure (e.g., predator signs). Nests too high to view directly were checked using an extendable, telescoping mirror to determine contents. We avoided flushing incubating or brooding adults from nests to minimize nest disturbance and abandonment and recorded those nests as active. When possible, we took different routes to check nests to reduce footpaths or other cues predators might employ to detect nests. Nests were checked more frequently (i.e., daily or every other day) as nestlings became fully feathered to determine accurate fledging or failure date.

Often, nests were empty when checked on days 7-10 post-hatch. To classify a nest as successful, we had to observe a host chick in the nest at least 8 days post-hatch because our analysis of $>50$ nests of multiple species monitored with video cameras indicated nestlings did not fledge earlier than 8 days post-hatch. Moreover, 
most nestlings can fly and escape predators at this age (Streby and Andersen 2013). If we did not observe a host nestling $\geq 8$ days post-hatch, we classified that nest as failed.

\section{Vegetation sampling}

After young fledged or nests failed, we conducted vegetation surveys using a modified Breeding Biology Research and Monitoring Database protocol (BBIRD, Martin et al. 1997) to determine nest-site characteristics. We recorded canopy cover ( $\%)$ using a spherical densiometer and mean canopy height $(\mathrm{m})$ using a clinometer. We established two circular plots around the nest, one with a 5-m radius (nest-site scale) and the second with an 11.3-m radius (nest-patch scale). We placed stakes at the four cardinal directions in both plots to create four quadrants per circle. For each quadrant within the nest-site scale, we recorded leaf litter depth $(\mathrm{mm})$ using a ruler, number of cane, shrub, and vine stems $>0.3 \mathrm{~m}$ in height within a $1-\mathrm{m}^{2}$ plot, and average height (m) of the shrub layer. We recorded percentage of green ground cover (i.e., grasses, forbs, shrubs, and vines), brush, leaf litter, fallen logs, and cane within each 5-m radius quadrant as well.

Within the nest-patch scale, we recorded the number of saplings ( $<2.5 \mathrm{~cm}$ diameter at breast height [dbh]; $>30 \mathrm{~cm}$ tall), poles (2.5-8 cm dbh), small (8.1-23 cm dbh), medium (23.1-38 cm dbh), and large $(>38 \mathrm{~cm} \mathrm{dbh})$ trees, small $(\leq 12 \mathrm{~cm} \mathrm{dbh} ;>1.4 \mathrm{~m}$ tall $)$ and large ( $>12 \mathrm{~cm} \mathrm{dbh;}>1.4 \mathrm{~m}$ tall) snags, and vine tents. Vine tents are umbrella-shaped growths of vines that grow on and cover a tree or shrub and are prime substrates for many passerine nests (e.g., Greenberg and Gradwohl 1983, Auer et al. 2007). Additionally, we determined understory density for both nest-site and nest-patch scales by placing a $2.5-\mathrm{m}$ cover board at the plot center and recorded the percentage of the board that was covered by vegetation at five height classes: $0.00-0.50 \mathrm{~m}, 0.51-1.00 \mathrm{~m}$, 1.01-1.50 m, 1.51-2.00 m, and 2.01-2.50 m (Nudds 1977). We recorded vegetation density at all four cardinal directions for each 5-m radius quadrant.

\section{Video monitoring}

We deployed video camera systems recording $24 \mathrm{hr}$ per day at 81 nests to determine nest fate and predator identity. Criteria for camera placement included presence of cowbird or host nestlings or nests that had reached incubation stage (to reduce probability of abandonment [Ball and Bayne 2012]), and accessibility for installation. Camera systems consisted of a Supercircuits monopower infrared camera (PC177IR-1color, Liberty Hill, TX), a micro-digital video recorder (DVR; AKR-100S, Korea), and a 12-V deep-cycle marine battery.

To minimize disturbance and maintain a clear view of nests, we mounted camouflaged cameras onto cryptic dowels and placed them $\sim 0.5 \mathrm{~m}$ from active nests. Foliage was minimally manipulated to permit camera monitoring, but to retain nest concealment. We placed DVRs and batteries in camouflaged bins $\sim 10 \mathrm{~m}$ from nests to reduce disturbance when memory cards and batteries were changed, which occurred every 3 and 6 days, respectively. Additionally, we sprayed video cables with a rodent repellent (RoPel Animal and Rodent Repellent, San Leandro, CA) to deter chewing by mammals. Once nests failed or fledged, we relocated camera systems to other suitable, active nests. Although Pietz and Granfors (2000) and Benson et al. (2010b) suggested camera systems do not affect nest success, we set up systems as quickly and quietly as possible to reduce the probability of abandonment or disturbance at the nest.

\section{Video review}

Once digital video data were collected, we reviewed the videos to determine nest fate. We reviewed $\sim 13,500$ hours (i.e., 562.5 days) of video with camera systems deployed between 1-13 days per nest. Nest success was defined as at least one host chick fledging from a nest, and failure was defined as no host chicks fledging from the nest. A cowbird-parasitized nest that fledged no host chicks was a failed nest. A nest with both fledged and depredated host chicks was considered successful for the nest success analyses, and the predator (if identified) was used for the predator-specific pattern analyses. We identified predators to species when possible and recorded nestling age at time of death or fledging.

\section{Statistical analyses}

We performed all statistical analyses with $\mathrm{R}$ statistical software 3.6.0 (R Core Team 2019). We set the significance level at 5\% and reported $95 \%$ confidence intervals (CIs) and means with standard errors (SEs). Prior to conducting our main analyses, we ran several exploratory analyses to exclude or clarify any potential biases that could affect our DSR results. All DSRs were calculated using the logistic exposure method (Shaffer 2004) to determine the probability a nest would survive from day to day.

First, to determine if the unknown fates $(n=138 / 282)$ affected our DSR estimates, we calculated our overall DSR (i.e., across sites and years) with unknown fates removed from analyses ( 0.929 \pm 0.01 ). To provide more liberal and conservative overall DSR results, we also changed all unknown fates to successful $(0.933$ $\pm 0.01)$ or failure $(0.929 \pm 0.01)$, respectively. As the $95 \%$ CIs overlapped among these DSR categories, unknown fates were retained in the analyses as originally assigned.

Second, to determine if our estimated nest termination date (i.e., from field data) affected our DSR estimates, we compared camera-monitored nest DSRs obtained with the field-estimated and video-determined nest termination dates. The DSRs did not differ $(0.932 \pm 0.01$ with field date vs. $0.922 \pm 0.01$ with video date) as the $95 \%$ CIs overlapped. We retained estimated dates for all nests for consistency.

Third, Pietz and Granfors (2000) and Benson et al. (2010b) determined camera systems did not appear to influence nest success; however, Richardson et al. (2009) reported camera systems reduced predation rates on songbird nests. Therefore, we tested the effect of cameras on parasitism and predation rates. The DSRs did not differ $(P=0.08)$ between parasitized noncamera nests $(0.911 \pm 0.01)$ and parasitized camera nests $(0.951$ $\pm 0.02)$. However, cameras had a significant, negative influence on cowbird parasitism rates $(-1.37 \pm 0.46, P=0.003)$, indicating camera nests were less likely to be parasitized than non-camera nests. Although cowbirds were less likely to parasitize camera nests, DSRs did not differ between parasitized camera nests and non-parasitized camera nests. Overall, DSR was not significantly different between non-camera nests $(0.929 \pm 0.01)$ and camera nests $(0.932 \pm 0.01 ; P=0.79)$; therefore, we included both camera and non-camera nests in our analyses when applicable. Moreover, there was no difference $(P=0.43)$ in the overall DSR between the two largest sample-sized species: Indigo Buntings (Passerina cyanea) and Northern Cardinals (Cardinalis cardinalis; Table 1). 
Table 1. Daily Survival Rates (DSRs) and standard errors (SEs) for all active Indigo Bunting (Passerina cyanea; INBU; $n=143$ ) and Northern Cardinal (Cardinalis cardinalis; NOCA; $n=97$ ) nests at Rattlesnake Ridge (RSR), Saint Francis National Forest (SFNF), Scrubgrass Bayou (SGB), and Trusten Holder Wildlife Management Area (THWMA) during summers 2010-2012 in east-central Arkansas, USA. We calculated DSRs based on the logistic exposure method (Shaffer 2004).

\begin{tabular}{|c|c|c|c|c|c|c|c|c|c|c|c|}
\hline \multirow[t]{3}{*}{ Year } & \multirow[t]{3}{*}{ Species } & \multicolumn{8}{|c|}{ Location } & \multicolumn{2}{|c|}{ Mean } \\
\hline & & \multicolumn{2}{|c|}{ RSR } & \multicolumn{2}{|c|}{ SFNF } & \multicolumn{2}{|c|}{ SGB } & \multicolumn{2}{|c|}{ THWMA } & & \\
\hline & & DSR & SE & DSR & SE & DSR & SE & DSR & SE & DSR & SE \\
\hline \multirow[t]{2}{*}{2010} & INBU & 0.935 & 0.02 & NA & NA & 0.905 & 0.03 & 0.928 & 0.01 & 0.925 & 0.01 \\
\hline & NOCA & 0.956 & 0.02 & NA & NA & 0.913 & 0.06 & 0.924 & 0.01 & 0.930 & 0.01 \\
\hline \multirow[t]{2}{*}{2011} & INBU & NA & NA & 0.974 & 0.03 & NA & NA & NA & NA & 0.974 & 0.03 \\
\hline & NOCA & NA & NA & 0.906 & 0.04 & NA & NA & NA & NA & 0.906 & 0.04 \\
\hline \multirow[t]{2}{*}{2012} & INBU & 0.941 & 0.03 & NA & NA & 0.870 & 0.05 & 0.945 & 0.01 & 0.938 & 0.01 \\
\hline & NOCA & 0.865 & 0.12 & NA & NA & 0.864 & 0.07 & 0.922 & 0.02 & 0.916 & 0.02 \\
\hline \multirow[t]{2}{*}{ Mean } & INBU & NA & NA & NA & NA & NA & NA & NA & NA & 0.932 & 0.01 \\
\hline & NOCA & NA & NA & NA & NA & NA & NA & NA & NA & 0.924 & 0.01 \\
\hline
\end{tabular}

The 10 understory density variables were highly correlated $(\mathrm{r}>$ 0.44, $P<0.001$ ). Thus, we performed a Principal Component Analysis to obtain fewer, uncorrelated understory variables. The first two principal components, PC1 and PC2, explained $~ 83 \%$ of the variation in these understory density variables. Specifically, as $\mathrm{PC} 1$ decreased, mean understory density vegetation increased at nests for all height classes $(0.0-2.5 \mathrm{~m})$ at the nest-site $(5-\mathrm{m}$ radius) and nest-patch (11.3-m radius) scales (Fig. 2). Additionally, as PC2 increased, the upper mean vegetation density $(1.5-2.5 \mathrm{~m})$ at the nest-patch scale (11.3-m radius) increased, and as PC2 decreased, the lower mean vegetation density $(0.0-1.5 \mathrm{~m})$ at the nest-site scale (5-m radius) increased (Fig. 2). Thus, we used both $\mathrm{PC} 1$ and $\mathrm{PC} 2$ in subsequent analyses to represent mean understory vegetation density.

Fig. 2. Relationship between the first two principal components (PC1 and PC2) from a Principal Component Analysis and mean percent understory vegetation of all height classes at both the nest-site (5-m radius) and nest-patch (11.3-m radius) scales for songbirds nesting in bottomland hardwood forests in eastcentral Arkansas, USA, summers 2010-2012. Avg1-Avg5 represent the height classes $(0.00-0.50 \mathrm{~m}, 0.51-1.00 \mathrm{~m}, 1.01-1.50$ $\mathrm{m}, 1.51-2.00 \mathrm{~m}$, and $2.01-2.50 \mathrm{~m}$, respectively) for the nest-site scale, and Avg6-Avg10 represent the same height classes for the nest-patch scale.

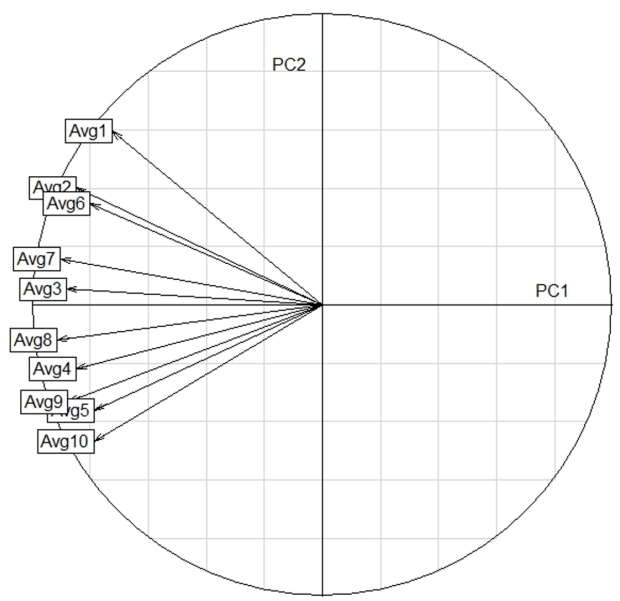

We conducted two main analyses. First, we calculated DSRs at each study site across years. We did not find any significant differences in DSRs among sites and years; therefore, we combined all sites and years. Second, we conducted a multinomial logistic regression of daily nest predation rates (DPRs). Predatorspecific patterns may vary temporally or among habitat features, which may influence nest success; therefore, elucidating trends among predators instead of collectively is most biologically informative (e.g., Benson et al. 2010a, Chiavacci et al. 2014).

We performed all our analyses in three stages. In stage 1, we determined which temporal and biological variables were the best predictors of songbird DSR and predator DPR. Temporal variables were nest stage (nest building/egg laying, incubating, brooding) and month the nest was active. Biological variables were species and parasitism (parasitized or not). We also considered relevant two-way interactions (i.e., nest stage and parasitism, species and month) among these variables. In stage 2, we determined which habitat variables were the best predictors of songbird DSR and predator DPR; stage 3 consisted of combining the selected variables from stages 1 and 2 .

At each stage, we conducted model selection using the $\mathrm{R}$ function dredge from package MuMIn (Barton 2020) and adopted an information-theoretic approach with the Akaike Information Criterion corrected for small samples $\left(\mathrm{AIC}_{\mathrm{c}}\right.$; Burnham and Anderson 2002) to select the best-supported model. When models were equivalent $\left(\Delta \mathrm{AIC}_{\mathrm{c}}<2\right)$, we applied the principle of parsimony. For stage 3, we used a Spearman's rank correlation test before model selection on the selected predictors from stages 1 and 2 .

Because the nest survival global model of stage 2 did not converge, we ran univariate models for each habitat variable and selected the variables from models with $\Delta \mathrm{AIC}_{\mathrm{c}}<2$. Using these top four variables, we used the dredge function to establish which model best-predicted nest survival.

To determine which variables influenced specific predator groups, we ran a multinomial logistic regression using the function multinom from package nnet (Venables and Ripley 2002) with the following response variables: snake, cowbird, avian, and mammalian. For stage 2 , we selected a subset of variables we thought may best influence predator groups (e.g., Benson et al. 
Table 2. Number of failure types and successful attempts for camera (C) and non-camera (NC) nests for each songbird species located in east-central Arkansas, USA, summers 2010-2012. Species include Carolina Wren(CARW; Thryothorus ludovicianus), Hooded Warbler (HOWA; Setophaga citrina), Indigo Bunting (INBU; Passerina cyanea), Kentucky Warbler (KEWA; Geothlypis formosa), Northern Cardinal (NOCA; Cardinalis cardinalis), Prothonotary Warbler (PROW; Protonotaria citrea), Swainson's Warbler (SWWA; Limnothlypis swainsonii), White-eyed Vireo (WEVI; Vireo griseus), Wood Thrush (WOTH; Hylocichla mustelina), and Yellow-billed Cuckoo (YBCU; Coccyzus americanus). Cracked indicates cracked eggs and Parasitized indicates parasitized by Brown-headed Cowbird (Molothrus ater). We located 282 active songbird nests; however, two nests were partially depredated. To account for these partial depredations, our total nests value is augmented by two. Specifically, one NOCA nest was partially depredated and successful and one INBU nest was partially depredated and the remaining nestling fates unknown.

\begin{tabular}{|c|c|c|c|c|c|c|c|c|c|c|c|c|c|c|c|c|c|c|c|}
\hline \multirow{3}{*}{$\begin{array}{c}\text { Fate } \\
\text { Species }\end{array}$} & \multicolumn{6}{|c|}{ Depredation } & \multicolumn{2}{|c|}{ Parasitized } & \multicolumn{6}{|c|}{ Other } & \multicolumn{2}{|c|}{ Unknown } & \multicolumn{2}{|c|}{ Successful } & \multirow[b]{3}{*}{ Total } \\
\hline & \multicolumn{2}{|c|}{ Avian } & \multicolumn{2}{|c|}{ Mammalian } & \multicolumn{2}{|c|}{ Reptilian } & \multirow[b]{2}{*}{$\mathrm{C}$} & \multirow[b]{2}{*}{$\mathrm{NC}$} & \multicolumn{2}{|c|}{ Abandoned } & \multicolumn{2}{|c|}{ Cracked } & \multicolumn{2}{|c|}{ Weather } & \multirow[b]{2}{*}{$\mathrm{C}$} & \multirow[b]{2}{*}{$\mathrm{NC}$} & \multirow[b]{2}{*}{$\mathrm{C}$} & \multirow[b]{2}{*}{$\mathrm{NC}$} & \\
\hline & $\mathrm{C}$ & $\mathrm{NC}$ & $\mathrm{C}$ & $\mathrm{NC}$ & $\mathrm{C}$ & $\mathrm{NC}$ & & & $\mathrm{C}$ & $\mathrm{NC}$ & $\mathrm{C}$ & $\mathrm{NC}$ & $\mathrm{C}$ & $\mathrm{NC}$ & & & & & \\
\hline CARW & 1 & 0 & 1 & 0 & 0 & 0 & 0 & 0 & 1 & 0 & 0 & 0 & 0 & 0 & 1 & 3 & 0 & 1 & 8 \\
\hline HOWA & 1 & 0 & 1 & 0 & 0 & 0 & 1 & 0 & 0 & 0 & 0 & 0 & 1 & 0 & 0 & 0 & 0 & 0 & 4 \\
\hline INBU & 3 & 0 & 2 & 0 & 1 & 0 & 1 & 26 & 7 & 10 & 0 & 6 & 1 & 0 & 6 & 55 & 18 & 8 & 144 \\
\hline KEWA & 0 & 0 & 0 & 0 & 1 & 0 & 0 & 0 & 0 & 0 & 0 & 0 & 0 & 0 & 0 & 0 & 0 & 0 & 1 \\
\hline NOCA & 3 & 0 & 2 & 0 & 3 & 0 & 0 & 2 & 1 & 4 & 1 & 0 & 0 & 0 & 4 & 58 & 8 & 12 & 98 \\
\hline PROW & 0 & 0 & 1 & 0 & 3 & 0 & 0 & 0 & 0 & 0 & 0 & 0 & 0 & 1 & 0 & 1 & 0 & 0 & 6 \\
\hline SWWA & 0 & 0 & 0 & 0 & 2 & 0 & 0 & 1 & 0 & 1 & 0 & 0 & 0 & 0 & 0 & 0 & 1 & 0 & 5 \\
\hline WEVI & 0 & 0 & 0 & 0 & 0 & 0 & 0 & 0 & 1 & 0 & 0 & 1 & 0 & 0 & 1 & 3 & 0 & 1 & 7 \\
\hline WOTH & 1 & 0 & 0 & 0 & 0 & 0 & 0 & 0 & 0 & 0 & 0 & 0 & 0 & 0 & 0 & 2 & 0 & 2 & 5 \\
\hline YBCU & 0 & 0 & 1 & 0 & 0 & 0 & 0 & 0 & 0 & 0 & 0 & 0 & 0 & 0 & 0 & 5 & 0 & 0 & 6 \\
\hline Total & 9 & 0 & 8 & 0 & 10 & 0 & 2 & 29 & 10 & 15 & 1 & 7 & 2 & 1 & 12 & 127 & 27 & 24 & 284 \\
\hline
\end{tabular}

2009, Bellamy et al. 2018). Variables included percent canopy cover, canopy height, leaf litter depth, total stems, shrub height, percent ground cover, total trees, snags, and vine tents, and PC1 and PC2 from mean percent understory cover.

\section{RESULTS}

We located 282 active songbird nests for 10 species among the four study sites during summers 2010-2012; Kentucky Warbler was the least common $(n=1)$ and Indigo Bunting the most $(n$ $=143$, Table 2). Notably, Indigo Bunting and Northern Cardinal comprised $85 \%(n=240 / 282)$ of all nests located; therefore, our results are heavily influenced by these two species. Yet, despite their small sample sizes, the remaining 8 species ( $n=42$ nests) are important to consider, as they are part of the avian community within these forests and comprise several species of conservation concern.

Of 282 songbird nests, 231 nests completely failed ( $82 \%$ ), and two nests were partially depredated (Table 2). A Blue Jay took one Indigo Bunting chick from a brood of four host chicks. The fates of the remaining nestlings were unknown because the camera system malfunctioned before nest fate could be recorded. The second partial predation event occurred at a Northern Cardinal nest. Two chicks fledged but one remained in the nest for an additional 2 days, at which time a rat snake consumed the last chick.

Of the failed nests, $\sim 60 \%$ ( $n=138 / 231)$ failed due to unknown causes. Although some predators were not recorded by camera systems, we identified three taxonomic classes from 27 predation events (Table 3); predation accounted for $\sim 29 \%(n=27 / 94)$ of all known nest failures (Table 2). The only reptilian predator was black rat snake (Pantherophis obsoletus; $n=10$ ), which also was the most frequent predator. Mammalian predators included Virginia opossum (Didelphis virginiana; $n=4$ ), northern raccoon (Procyon lotor; $n=3$ ), and Eastern gray squirrel (Sciurus carolinensis; $n=1$; Table 3). Avian predators included Redshouldered Hawk (Buteo lineatus; $n=2$ ), Broad-winged Hawk (Buteo platypterus; $n=3$ ), Barred Owl (Strix varia; $n=2)$, Blue Jay (Cyanocitta cristata; $n=1$ ), and crow (Corvus sp.; $n=1$; Table $3)$. Brood parasitism accounted for 33\% $(n=31 / 94)$ of all known nest failures (Table 2).

Overall DSR among sites and years was $0.930 \pm 0.01$. DSRs for all species ranged from $0.873 \pm 0.03$ to $0.938 \pm 0.01$ across locations and years (Table 4). Nest stage was the best predictor of nest survival for stage 1 (Table 5), suggesting DSR did not differ among species. Number of vine tents was the bestsupported model for stage 2 (Table 5). Although number of vine stems had equal support (i.e., $\Delta \mathrm{AIC}_{\mathrm{c}}<2, k=2$ ), it was not significant $(P=0.08)$; therefore, we only selected number of vine tents $(P=0.04)$. Number of vine tents and nest stage were not correlated $(\rho=-0.01, P=0.69)$; therefore, we combined both predictors in the same model for stage 3 , which was the bestsupported model (Table 5). Specifically, nests in the building/ laying stage had the highest likelihood of survival $(0.879 \pm 0.03)$, followed by incubation $(0.681 \pm 0.07)$, then brooding stage $(0.639$ $\pm 0.07)$. Additionally, DSR decreased with more vine tents surrounding the nest $(\beta=-0.04 \pm 0.02$, Table 6$)$.

The best and only supported model of predator-specific patterns for stage 1 included parasitism and species $\left(\mathrm{AIC}_{\mathrm{c}}=335.09 \mathrm{vs}\right.$. global model $\left.\mathrm{AIC}_{\mathrm{c}}=356.83\right)$. Notably, parasitism positively influenced the probability of nest predation by avian predators and negatively influenced the probability of nest predation by mammalian predators (Table 7). Two habitat-variable models of predator-specific patterns had a $\triangle \mathrm{AICc}<2$ for stage 2 (Table 8 ). Because many habitat variables were correlated with parasitism, we could not combine stages 1 and 2 for predator-specific patterns. According to the most parsimonious model of stage 2, habitat variables positively influenced certain predator groups while negatively or not influencing others. For example, canopy cover 
Table 3. Number of predation events by predator for each songbird species in east-central Arkansas, USA, summers 2010-2012. Species include Carolina Wren (CARW; $n=8$ ), Hooded Warbler (HOWA; $n=4$ ), Indigo Bunting (INBU; $n=143$ ), Kentucky Warbler (KEWA; $n=1$ ), Northern Cardinal (NOCA; $n=97$ ), Prothonotary Warbler (PROW; $n=6$ ), Swainson's Warbler (SWWA; $n=5$ ), White-eyed Vireo (WEVI; $n=7$ ), Wood Thrush (WOTH; $n=5$ ), and Yellow-billed Cuckoo (YBCU; $n=6$ ). ${ }^{\mathrm{a}}$ Pantherophis obsoletus, ${ }^{\mathrm{b}}$ Buteo lineatus, ${ }^{\mathrm{c}}$ Buteo platypterus, ${ }^{\mathrm{d}}$ Strix varia,,${ }^{\mathrm{e}}$ Cyanocitta cristata, ${ }^{\mathrm{f}}$ Corvus $\mathrm{sp} .,{ }^{\mathrm{g}}$ Didelphis virginiana, ${ }^{\mathrm{h}}$ Procyon lotor, and ${ }^{\mathrm{i}}$ Sciurus carolinensis.

\begin{tabular}{|c|c|c|c|c|c|c|c|c|c|c|}
\hline Species & $\begin{array}{c}\text { Black Rat } \\
\text { Snake }^{\mathrm{a}}\end{array}$ & $\begin{array}{c}\text { Red- } \\
\text { shouldered } \\
\text { Hawk }^{b}\end{array}$ & $\begin{array}{l}\text { Broad- } \\
\text { winged } \\
\text { Hawk }^{c}\end{array}$ & $\begin{array}{c}\text { Barred } \\
\mathrm{Owl}^{\mathrm{d}}\end{array}$ & Blue Jay $^{\mathrm{e}}$ & Crow sp. ${ }^{f}$ & $\begin{array}{c}\text { Virginia } \\
\text { Opossum }^{\mathrm{g}}\end{array}$ & $\begin{array}{l}\text { Northern } \\
\text { Raccoon }\end{array}$ & $\begin{array}{c}\text { Eastern } \\
\text { Gray } \\
\text { Squirrel }^{\mathrm{i}}\end{array}$ & Total \\
\hline CARW & 0 & 0 & 1 & 0 & 0 & 0 & 1 & 0 & 0 & 2 \\
\hline HOWA & 0 & 0 & 1 & 0 & 0 & 0 & 0 & 1 & 0 & 2 \\
\hline INBU & 1 & 0 & 0 & 2 & 1 & 0 & 0 & 2 & 0 & 6 \\
\hline KEWA & 1 & 0 & 0 & 0 & 0 & 0 & 0 & 0 & 0 & 1 \\
\hline NOCA & 3 & 1 & 1 & 0 & 0 & 1 & 2 & 0 & 0 & 8 \\
\hline PROW & 3 & 0 & 0 & 0 & 0 & 0 & 0 & 0 & 1 & 4 \\
\hline SWWA & 2 & 0 & 0 & 0 & 0 & 0 & 0 & 0 & 0 & 2 \\
\hline WEVI & 0 & 0 & 0 & 0 & 0 & 0 & 0 & 0 & 0 & 0 \\
\hline WOTH & 0 & 1 & 0 & 0 & 0 & 0 & 0 & 0 & 0 & 1 \\
\hline YBCU & 0 & 0 & 0 & 0 & 0 & 0 & 1 & 0 & 0 & 1 \\
\hline Total & 10 & 2 & 3 & 2 & 1 & 1 & 4 & 3 & 1 & 27 \\
\hline
\end{tabular}

Table 4. Daily Survival Rates (DSRs) and standard errors (SEs) for all active nests at Rattlesnake Ridge (RSR), Saint Francis National Forest (SFNF), Scrubgrass Bayou (SGB), and Trusten Holder Wildlife Management Area (THWMA) during summers 2010-2012 in east-central Arkansas, USA. We calculated DSRs based on the logistic exposure method (Shaffer 2004).

\begin{tabular}{|c|c|c|c|c|c|c|}
\hline \multirow[b]{2}{*}{$\begin{array}{l}\text { Loca- } \\
\text { tion }\end{array}$} & \multicolumn{2}{|c|}{2010} & \multicolumn{2}{|c|}{2011} & \multicolumn{2}{|c|}{2012} \\
\hline & DSR & $\mathrm{SE}$ & DSR & SE & DSR & SE \\
\hline RSR & 0.938 & 0.01 & NA & NA & 0.930 & 0.03 \\
\hline SFNF & NA & NA & 0.932 & 0.02 & NA & NA \\
\hline SGB & 0.904 & 0.03 & NA & NA & 0.873 & 0.03 \\
\hline $\begin{array}{l}\text { TH- } \\
\text { WMA }\end{array}$ & 0.932 & 0.01 & NA & NA & 0.935 & 0.01 \\
\hline Mean & 0.925 & 0.02 & 0.932 & 0.02 & 0.913 & 0.02 \\
\hline
\end{tabular}

negatively influenced the probability of nest predation by snakes, cowbirds, and other avian predators, but positively influenced the probability of nest predation by mammalian predators; shrub height positively influenced the probability of nest predation by cowbirds and other avian predators, but negatively influenced the probability of nest predation by snakes and did not affect the probability for mammalian predators (Table 7). Further, number of snags positively influenced the probability of nest predation by cowbirds and mammalian predators but did not influence the probability of nest predation by snakes and other avian predators; vegetation density negatively influenced the probability of nest predation by snakes and mammals, but positively influenced the probability of nest predation by cowbirds and did not influence the probability of nest predation by other avian predators (Table 7).

\section{DISCUSSION}

Causes of nest failure may include severe weather (Pietz et al. 2012), interspecific competition (Etterson et al. 2007), and starvation (Etterson et al. 2007, Pietz et al. 2012), yet predation is often most common. In our study, $\sim 29 \%$ of known nest failures were caused by non-cowbird predation. Brood parasitism, which can be viewed as a form of predation (Benson et al. 2010b), accounted for $33 \%$ of known nest failures. Thus, by combining these two failure types, predation was the most prevalent cause of nest failure, as frequently supported in the literature (e.g., Ricklefs 1969, Reidy and Thompson III 2012, Bellamy et al. 2018).

Although $26 \%(n=74 / 282)$ of songbird nests were parasitized, we could not assess if host eggs/nestlings were removed, as most of these nests were not monitored with video cameras. Additionally, camera systems often were deployed during late incubation or early nestling periods when cowbirds were less likely to eject host eggs or interfere with nests. Further, it is unknown whether the nest was abandoned because it was parasitized or if the adults abandoned for other reasons (e.g., stress, perceived risk, or death). Regardless, our overall parasitism rate was slightly lower than that of Swainson's Warbler (Limnothlypis swainsonii) nests studied previously in our Arkansas study area (36\%; Benson et al. 2010a), though only $20 \%(n=1 / 5)$ of Swainson's Warbler nests were parasitized in our study.

Although we identified several causes of nest failure, we could not determine the cause of most failed nests for lack of evidence. For example, several nests were ripped or hanging from the nesting substrate, indicating either weather or an unknown predator was responsible. Even at nests with camera systems, 11 failures occurred without being captured on video. Camera systems occasionally malfunctioned due to loss of battery power, memory cards reaching capacity, or cables being chewed by mammals. Additionally, strong winds blew some cameras out of nest view or blew vegetation in front of cameras.

Depending on the habitat and predator community, camera systems may or may not be ideal tools to assist with data collection. Neophobia may deter several predators from approaching camera systems including corvids, some raptors, and small mammals (Richardson et al. 2009). The scent or presence of researchers or camera equipment also may prevent predators from investigating the area, or contrarily, it may lure them to a nest (Ibáñez-Álamo et al. 2012 and references therein). Moreover, 
Table 5. Three-stage model selection for best-supported temporal and biological factors (Stage 1), habitat factors (Stage 2), and the combination of the best supported factors from stages 1 and 2 (Stage 3) for songbird nest survival during summers 2010-2012 in eastcentral Arkansas, USA. Abbreviations are as follows: $k$ : number of parameters, $\triangle \mathrm{AIC}_{\mathrm{c}}$ : difference in corrected Akaike's Information Criterion $\left(\Delta \mathrm{AIC}_{\mathrm{c}}=\mathrm{AIC}_{\mathrm{ci}}-\min . \mathrm{AIC}_{\mathrm{c}}\right), \omega_{\mathrm{i}}$ : model weight (i.e., explanatory power), and LL: $\log$ likelihood. Only models with $\Delta \mathrm{AIC} \mathrm{C}_{\mathrm{c}}<$ 2 are presented for each stage of selection. $\$$ indicates the selected model per stage, and : indicates an interaction effect.

\begin{tabular}{|c|c|c|c|c|}
\hline Model $^{\dagger}$ & $k$ & $\Delta \mathrm{AIC}_{c}$ & $\omega_{i}$ & $\mathrm{LL}$ \\
\hline Stage 1: Selection of temporal and biological factors & 3 & 0.00 & 0.41 & -438.54 \\
\hline \multicolumn{5}{|l|}{ Nest stage } \\
\hline Intercept & 1 & 1.18 & 0.23 & -441.14 \\
\hline Nest stage + parasitized & 4 & 1.29 & 0.21 & -438.18 \\
\hline Nest stage + parasitized + nest stage:parasitized & 6 & 1.97 & 0.15 & -436.50 \\
\hline \multicolumn{5}{|l|}{ Stage 2: Selection of habitat factors } \\
\hline Saplings + vine tents & 3 & 0.00 & 0.16 & -434.77 \\
\hline Small trees + vine tents & 3 & 0.36 & 0.13 & -434.95 \\
\hline Saplings + small trees + vine tents & 4 & 0.45 & 0.12 & -433.99 \\
\hline Saplings + vines & 3 & 0.52 & 0.12 & -435.03 \\
\hline Vine tents & 2 & 0.65 & 0.11 & -436.10 \\
\hline Saplings + vines + vine tents & 4 & 1.04 & 0.09 & -434.28 \\
\hline Saplings + small trees + vines & 4 & 1.30 & 0.08 & -434.41 \\
\hline Saplings + small trees + vines + vine tents & 5 & 1.74 & 0.07 & -433.62 \\
\hline Small trees + vines & 3 & 1.87 & 0.06 & -435.71 \\
\hline Vines & 2 & 1.94 & 0.06 & -436.75 \\
\hline \multicolumn{5}{|l|}{ Stage 3: Combination of Stages 1 and 2} \\
\hline Nest stage + vine tents & 4 & 0.00 & 0.50 & -433.52 \\
\hline Vine tents & 2 & 1.12 & 0.29 & -436.10 \\
\hline Nest stage & 3 & 2.91 & 0.12 & -435.99 \\
\hline Intercept & 1 & 3.35 & 0.09 & -438.22 \\
\hline
\end{tabular}

${ }^{\dagger}$ The lowest Akaike Information Criterion corrected for small samples (AIC $\mathrm{c}_{\mathrm{c}}$ ) values were 883.12 for Stage 1 , 875.57 for Stage 2 , and 875.09 for Stage 3.

Table 6. Parameter estimates with standard errors (SEs) for the effect of nest stage and number of vine tents on songbird daily survival rate (DSR) during summers 2010-2012 in east-central Arkansas, USA. Estimates are DSR (on the logit scale) for the intercept representing the nest-building and egg-laying stage, differences in DSR between the nest-building/egg-laying and other stages (i.e., incubation [I] and brooding [B]), and slope for number of vine tents.

\begin{tabular}{lll}
\hline \hline Parameter & Estimate & SE \\
\hline Intercept & 2.12 & 0.32 \\
Nest stage I & 0.78 & 0.34 \\
Nest stage B & 0.59 & 0.33 \\
Vine tents & -0.04 & 0.02 \\
\hline
\end{tabular}

a potential bias may occur when camera systems are deployed on nests that are later in the nesting cycle (i.e., nestling or late incubation stage; Benson et al. 2010b), and camera systems may influence DSRs (Richardson et al. 2009).

Of the nests monitored with camera systems, snakes were the primary predator $(n=10)$, which echoes findings of other songbird predation studies in the mid and southern USA. Snakes were the primary predators (or tied with avian predators) of songbirds in Arkansas, Illinois, Missouri, and Texas (Benson et al. 2010b, Cox et al. 2012a, Davis et al. 2019). Avian predators were the second most frequent followed by mammalian predators in our study. Notably, multiple species were included in the avian and mammalian taxonomic classes, whereas black rat snake was the only reptilian predator.
Of the recorded predation events in this study, $85 \%$ occurred during the nestling stage, indicating DSRs were higher during the incubation period than brooding phase; this has been reported in several other avian studies in the USA. In California, raptors preyed on Dusky Flycatcher (Empidonax oberholseri) nestlings more commonly than eggs (Liebezeit and George 2002), and rat snakes and raptors preyed upon Swainson's Warbler nestlings more frequently than eggs in Arkansas (Benson et al. 2010b). Further, predation was higher during the nestling stage for Acadian Flycatchers (Empidonax virescens) and Indigo Buntings in Missouri and Illinois (Cox et al. 2012a), and for multiple species in Texas (Reidy and Thompson III 2012).

One likely explanation for lower DSRs during brooding in our study is chicks are active; thus, chicks likely are more easily detected by predators. As nestlings develop and beg for more prey, adults visit the nest more frequently to satiate their appetites and remove fecal sacs. Therefore, predators may have used visual and auditory cues associated with this increased nest activity to locate prey in our study and others (e.g., Benson et al. 2010b). Further, previous research indicated snake predation rates increased as the nestling stage progressed, suggesting snakes use activity at nests to find nests more easily (Stake et al. 2005). Cowbird chicks also can increase the volume and frequency of begging in the nest, which may further attract attention of auditory predators. For example, chicks in parasitized Indigo Bunting nests begged more frequently and louder than chicks in non-parasitized nests in Missouri, and predation rates were significantly higher at parasitized nests than non-parasitized nests during the entire nesting cycle (Dearborn 1999). Moreover, parasitized American Redstart (Setophaga ruticilla) nests had 16-19\% higher failure rate than non-parasitized nests (Hannon et al. 2009). Both studies 
Table 7. Parameter estimates (with SEs) for the influence of (A) parasitism and (B) habitat characteristics on predator-specific daily nest predation rate (DPR) during summers 2010-2012 in east-central Arkansas, USA. Cowbird indicates Brown-headed Cowbird, No. indicates number of, and Veg. density 2 represents principal component 2 from a Principal Component Analysis of understory variables (see Figure 2). Estimates under (A) are DPR differences for each predator group between non-parasitized (intercept) and parasitized nests. Estimates under (B) are true intercepts for each predator group and slopes for all habitat variables.

\begin{tabular}{|c|c|c|c|c|}
\hline$\underline{\text { Parameter }}$ & Snake & Cowbird & Avian & Mammalian \\
\hline \multicolumn{5}{|l|}{ (A) Parasitism } \\
\hline Intercept & $0.76(0.25)$ & $11.77(0.50)$ & $7.74(289.44)$ & $43.92(0.22)$ \\
\hline Parasitized & -22.52 (NA) & $109.16(<0.01)$ & $31.14(<0.01)$ & $-22.66(<0.01)$ \\
\hline \multicolumn{5}{|l|}{ (B) Habitat characteristics } \\
\hline Intercept & $52.05(0.50)$ & $4.67(5.31)$ & $7.95(6.98)$ & $-49.96(0.20)$ \\
\hline Canopy cover $(\%)$ & $-0.45(0.03)$ & $-0.15(0.05)$ & $-0.17(0.07)$ & $0.48(0.02)$ \\
\hline Canopy height (m) & $-0.36(0.10)$ & $0.13(0.04)$ & $0.14(0.05)$ & $-0.02(0.05)$ \\
\hline Leaf litter depth (mm) & $-0.29(0.11)$ & $0.03(0.01)$ & $0.04(0.02)$ & $-0.41(0.10)$ \\
\hline No. stems & $-0.18(0.26)$ & $-0.37(0.11)$ & $-0.47(0.16)$ & $0.63(0.11)$ \\
\hline Shrub height (m) & $-1.41(0.75)$ & $1.08(0.26)$ & $0.69(0.31)$ & $-0.27(0.39)$ \\
\hline Ground cover $(\%)$ & $0.02(0.03)$ & $0.07(0.01)$ & $0.04(0.02)$ & $0.02(0.03)$ \\
\hline No. trees & $<0.01(0.01)$ & $-0.01(<0.01)$ & $<-0.01(0.01)$ & $0.03(0.01)$ \\
\hline No. snags & $0.03(0.14)$ & $0.21(0.07)$ & $-0.05(0.11)$ & $0.34(0.10)$ \\
\hline No. vine tents & $0.33(0.14)$ & $0.41(0.10)$ & $0.33(0.11)$ & $0.01(0.13)$ \\
\hline Veg. density $2(\%)$ & $-1.64(0.61)$ & $0.58(0.26)$ & $0.09(0.33)$ & $-0.90(0.44)$ \\
\hline
\end{tabular}

indicate vocalizations by nestlings, particularly cowbirds, may be an important cue utilized by predators when searching for nests.

Regardless of nesting stage and predator cues, research suggests birds are negatively affected when breeding in areas with higher perceived predation risk. For example, egg and clutch mass and clutch size may be reduced in areas with high levels of predation (Fontaine and Martin 2006). Further, nestlings developed at a faster rate, fledged sooner, and had lower body mass when predation risk was high (Remeš and Martin 2002). Similarly, Meadow Pipits (Anthus pratensis), which typically fledge 13 days after hatching, fledged as early as 9 days when the nest was attacked by a predator (Halupka 1998). Although Indigo Buntings generally fledge 9-12 days after hatching (Payne 2020) and Northern Cardinals often fledge 9-10 days after hatching (Halkin and Linville 2020), we observed both species fledging as early as 8 days post-hatch. Nestlings often fledge prematurely when nests are checked or disturbed (Jongsomjit et al. 2007), yet this did not occur with any camera nest in our study; the chicks that fledged early did so independently of researcher visits. A predator, near but off camera, may have caused early fledging, or these individuals may have had a higher perceived predation risk throughout the duration of their development to cause early fledging; both suggestions are speculative.

Our mean DSRs for Indigo Buntings $(0.932 \pm 0.01)$ and Northern Cardinals $(0.924 \pm 0.01)$ were similar to those reported in other studies. Median DSRs (with 95\% CIs) for Indigo Buntings and Northern Cardinals in the driftless area ecoregion (in parts of Iowa, Minnesota, and Wisconsin) were $0.953(0.914,0.974)$ and 0.945 (0.912, 0.967), respectively (Knutson et al. 2007) and mean DSR for Indigo Buntings in Missouri was 0.927 (0.905, 0.944; Reidy and Thompson 2018). However, Indigo Bunting nest survival was higher earlier in the breeding season (Reidy and Thompson 2018), which was contrary to our study, but in line with other avian studies (e.g., Grant et al. 2005, Knutson et al 2007 and references therein).

Surprisingly, not many vegetation characteristics influenced nest survival in our study, as reported elsewhere for forest-nesting avian species (Knutson et al. 2007, Reidy and Thompson 2018). Perhaps habitat characteristic variability was too low among nests. However, we found DSRs decreased as number of vine tents presumably enhancing vegetation concealment-increased. Unlike other studies (e.g., Liebezeit and George 2002, Knutson et al. 2007 and references therein) that supported the total-foliage hypothesis, nest survival in our study sites was lower in more vinecovered habitat. In particular, vine tents may act as an ecological trap in our study. Perhaps predators focused their search efforts in densely vegetated areas to increase their probability of locating nests, or perhaps predation pressure was so high in the area that concealment provided little benefit (Benson et al. 2010a). Either way, nest success was lower in areas that had more vine tents. Further, variability in influential predictors was high among predator groups (Table 7), thus indicating not all predators should be treated identically both when researchers assess the influence of predation, and importantly for management practices.

\section{Conservation implications}

Identification of predators via camera systems can assist managers in understanding why predation rates can vary across spatial scales (Cox et al. 2012b and references therein) and across species. Direct removal of predators may be an appropriate technique in certain habitats; however, indirect removal may be a more economical and effective long-term option. If land managers can manipulate habitat to disadvantage predators while simultaneously providing habitat favorable for nesting passerines, it may alleviate high predation pressure, especially for species of conservation concern and declining populations. Snakes, for example, often use corridors or habitat edges (Thompson III and 
Table 8. Best-supported models of habitat factors for predator-specific patterns during summers 2010-2012 in east-central Arkansas, USA. Abbreviations are as follows: $k$ : number of parameters, $\triangle \mathrm{AIC}_{\mathrm{c}}$ : difference in corrected Akaike's Information Criterion $\left(\Delta \mathrm{AIC} \mathrm{c}_{\mathrm{c}}\right.$ $=\mathrm{AIC}_{\mathrm{ci}}-\min . \mathrm{AIC}_{\mathrm{c}}$ ), $\omega_{\mathrm{i}}$ : model weight (i.e., explanatory power), and LL: log likelihood. Only models with $\Delta \mathrm{AIC} \mathrm{C}_{\mathrm{c}}<2$ are presented. Veg. density 1 and 2 represent principal components 1 and 2, respectively, from the Principal Component Analysis of vegetation variables (see Figure 2). ${ }^{\ddagger}$ indicates the selected model.

\begin{tabular}{|c|c|c|c|c|}
\hline Model $^{\dagger}$ & $k$ & $\Delta \mathrm{AIC}_{c}$ & $\omega_{i}$ & LL \\
\hline $\begin{array}{l}\text { Canopy cover }(\%)+\text { canopy height }(\mathrm{m})+\text { litter depth }(\mathrm{mm})+\text { no. stems }+ \text { shrub height }(\mathrm{m})+\text { ground cover }(\%) \\
+ \text { no. trees }+ \text { no. snags }+ \text { no. vine tents }+ \text { veg. density } 1(\%)+\text { veg. density } 2(\%)\end{array}$ & 48 & 0.00 & 0.72 & -203.39 \\
\hline $\begin{array}{l}\text { Canopy cover }(\%)+\text { canopy height }(\mathrm{m})+\text { litter depth }(\mathrm{mm})+\text { no. stems }+ \text { shrub height }(\mathrm{m})+\text { ground cover }(\%) \\
+ \text { no. trees }+ \text { no. snags }+ \text { no. vine tents }+ \text { veg. density } 2(\%)^{\ddagger}\end{array}$ & 44 & 1.94 & 0.28 & -210.54 \\
\hline
\end{tabular}

Ribic 2012). If managers could reduce the amount of edge habitat -while still leaving enough for species that depend on it - they not only could provide suitable habitat for area-sensitive songbirds but also reduce potential paths used by snakes and other predators. Importantly, as demonstrated in our study and others (e.g., Benson et al. 2010b, Chiavacci et al. 2014), predator-specific patterns can vary across habitats, species, and temporally; therefore, managers should consider techniques that would influence avian nest success for their specific region and habitat.

Although our results are skewed toward Northern Cardinals and Indigo Buntings (which comprised $85 \%$ of our studied nests), these conservation implications still are relevant for the avian coinhabitants in these bottomland forests, particularly as 9 predator species depredated nests of $9 / 10$ avian species. The two most consequential predators of nests identified in this study were Brown-headed Cowbirds and black rat snakes. We suggest populations of both species are likely augmented due to human alterations and may be exerting undue and unnaturally high pressure on nesting passerine populations in the bottomland forest ecosystem we studied, which are in permanently fragmented forests that also represent some of the largest remnant patches of bottomland forest in the MAV.

Specifically, cowbirds are thriving due to fragmentation of our forested system (e.g., Bernath-Plaisted et al. 2017) and presence of livestock (e.g., Goguen and Mathews 2001) especially along the levees surrounding the periphery of our study sites. These levees are, in part, managed by the agencies responsible for the administration of the forested reserves included in our study; thus, livestock use theoretically could be phased out. Because of altered hydrology resulting in deeper and prolonged spring floods of these bottomland preserves, Bader and Bednarz (2009) argued these phenomena may have exacerbated rat snake predation on nesting Mississippi Kites (Ictinia mississippiensis). Therefore, we recommend future conservation research and land management efforts focus on closely monitoring the populations of these two predator species. Predator and avian nest monitoring are particularly important because as temperatures rise with climate change, ectothermic activity and predation (e.g., by snakes) may increase, shifts in predator ranges may occur (Ibáñez-Álamo et al. 2015), or predators may increase nocturnal activity (Sperry et al. 2010); all these scenarios may influence nest success.

If avian populations are not maintained and begin to decline, many ecosystem services provided by birds (e.g., pollination or seed dispersal, control of arthropod populations) may decline as well (Şekercioğlu et al. 2004). Therefore, it is necessary for managers to manage habitat, potentially implement predator control techniques (of non-threatened predators) and incorporate local predator knowledge when designing habitat management plans (Lyons et al. 2015) to alleviate high predation pressure from passerines to facilitate successful reproduction and ultimately, population survival.

Responses to this article can be read online at: https://www.ace-eco.org/issues/responses.php/1897

\section{Acknowledgments:}

We thank S. Chiavacci, R. Cooper, M. DaSilva, J. Everitts, C. Foshee, J. Henson, J. Hopper, M. Howard, R. Manley, S. Miller, C. Phillips, B. Reiley, J. Roberts, and C. Ward for invaluable field assistance, V. Kearny for Figure 1, and reviewers and editors for draft improvements. Base funding for this research was provided by the Arkansas Game and Fish Commission and United States Fish and Wildlife Service through a State Wildlife Grant. Additional funding and other support were received from the Arkansas Audubon Society Trust, Arkansas Department of Parks and Tourism, Arkansas State University, United States Army Corps of Engineers Little Rock office, United States Fish and Wildlife Service White River Refuge, and United States Forest Service St. Francis National Forest District.

\section{LITERATURE CITED}

Arkansas Game and Fish Commission (AGFC) 2020. AGFC homepage. [online] URL: https://www.agfc.com/en/zonemap/774/

Auer, S. K., D. M. Logue, R. D. Bassar, and D. E. Gammon. 2007. Nesting biology of the Black-bellied Wren (Thryothorus fasciatoventris) in central Panama. Wilson Journal of Ornithology 119:71-76. https://doi.org/10.1676/06-008.1

Bader, T. J., and J. C. Bednarz. 2009. Reproductive success and causes of nest failures for Mississippi Kites: A sink population in eastern Arkansas? Wetlands 29:598-606. https://doi.org/10.1672/08-53.1 
Ball, J. R., and E. M. Bayne. 2012. Using video monitoring to assess the accuracy of nest fate and nest productivity estimates by field observation. The Auk 129:438-448. https://doi. org/10.1525/auk.2012.11224

Barton, K. 2020. MuMIn: Multi-Model Inference. R package version 1.43.17. [online] URL: https://CRAN.R-project.org/ package $=$ MuMIn

Bellamy, P. E., M. D. Burgess, J. W. Mallord, A. Cristinacce, C. J. Orsman, T. Davis, P. V. Grice, and E. C. Charman. 2018. Nest predation and the influence of habitat structure on nest predation of Wood Warbler Phylloscopus sibilatrix, a ground-nesting forest passerine. Journal of Ornithology 159:493-506. https://doi. org/10.1007/s10336-017-1527-7

Benson, T. J., N. M. Anich, J. D. Brown, and J. C. Bednarz. 2009. Swainson's Warbler nest-site selection in eastern Arkansas. The Condor 111:694-705. https://doi.org/10.1525/cond.2009.080074

Benson, T. J., N. M. Anich, J. D. Brown, and J. C. Bednarz. 2010a. Habitat and landscape effects on brood parasitism, nest survival, and fledgling production in Swainson's Warblers. Journal of Wildlife Management 74:81-93. https://doi.org/10.2193/2008-442

Benson, T. J., J. D. Brown, and J. C. Bednarz. 2010b. Identifying predators clarifies predictors of nest success in a temperate passerine. Journal of Animal Ecology 79:225-234. https://doi. org/10.1111/j.1365-2656.2009.01604.X

Bernath-Plaisted, J., H. Nenninger, and K. Koper. 2017. Conventional oil and natural gas infrastructure increases Brownheaded Cowbird (Molothrus ater) relative abundance and parasitism in mixed-grass prairie. Royal Society Open Science 4:170036. https://doi.org/10.1098/rsos. 170036

Buehler, D. A., P. B. Hamel, and T. Boves. 2020. Cerulean Warbler (Setophaga cerulea), version 1.0. In Birds of the World (A. F. Poole, Editor). Cornell Lab of Ornithology, Ithaca, NY, USA. https://doi.org/10.2173/bow.cerwar.01

Burnham, K. P., and D. R. Anderson. 2002. Model selection and multimodel inference. Springer, New York, New York, USA. https://doi.org/10.1007/b97636

Chiavacci, S. J., T. J. Bader, and J. C. Bednarz. 2014. Preferred nest site characteristics reduce predator-specific predation risk in a canopy-nesting raptor. Journal of Wildlife Management 78:1022-1032. https://doi.org/10.1002/jwmg.746

Colwell, M. 1992. Wilson's Phalarope nest success is not influenced by vegetation concealment. The Condor 94:767-772. https://doi.org/10.2307/1369262

Cox, W. A., F. R. Thompson III, and J. Faaborg. 2012a. Species and temporal factors affect predator-specific rates of nest predation for forest songbirds in the Midwest. The Auk 129:147-155. https://doi.org/10.1525/auk.2012.11169

Cox, W. A., F. R. Thompson, and J. Faaborg. 2012b. Landscape forest cover and edge effects on songbird nest predation vary by nest predator. Landscape Ecology 27:659-669. https://doi. org/10.1007/s10980-012-9711-X

Davis, H. T., A. M. Long, J. A. Baumgardt, T. A. Campbell, and M. L. Morrison. 2019. Factors Affecting Nest Success and
Predator Assemblage of Breeding Birds in Semiarid Grasslands. Rangeland Ecology \& Management 72:385-395. https://doi. org/10.1016/j.rama.2018.09.005

Dearborn, D. C. 1999. Brown-headed Cowbird nestling vocalizations and risk of nest predation. The Auk 116:448-457. https://doi.org/10.2307/4089378

Ellison, K. S., and C. A. Ribic. 2012. Nest defense: grassland bird responses to snakes. Pp. 149-160 in C. A. Ribic, F. R. Thompson III, and P. J. Pietz, editors. Video surveillance of nesting birds. Studies in Avian Biology (no. 43), University of California Press, Berkeley, CA, USA. https://doi.org/10.1525/california/9780520273139.003.0012

Etterson, M. A., L. R. Nagy, and T. R. Robinson. 2007. Partitioning risk among different causes of nest failure. The Auk 124:432-443. https://doi.org/10.1093/auk/124.2.432

Fontaine, J. J., and T. E. Martin. 2006. Parent birds assess nest predation risk and adjust their reproductive strategies. Ecology Letters 9:428-434. https://doi.org/10.1111/j.1461-0248.2006.00892. $\mathrm{x}$

Goguen, C. B., and N. E. Mathews 2001. Brown-headed Cowbird behavior and movements in relation to livestock grazing. Ecological Applications 11:1533-1544. https://doi.org/10.1890/1051-0761 (2001)011[1533:bhcbam]2.0.co;2

Grant, T. A., T. L. Shaffer, E. M. Madden, and P. J. Pietz. 2005. Time-specific variation in passerine nest survival: new insights into old questions. The Auk 122:661-672. https://doi.org/10.1093/ auk/122.2.661

Greenberg, R., and J. Gradwohl. 1983. Sexual roles in the DotWinged Antwren (Microrhopias quixensis), a tropical forest passerine. The Auk 100:920-925. https://doi.org/10.1093/ auk/100.4.920

Halkin, S. L. and S. U. Linville. 2020. Northern Cardinal (Cardinalis cardinalis), version 1.0. In Birds of the World (A. F. Poole and F. B. Gill, Editors). Cornell Lab of Ornithology, Ithaca, NY, USA. [online] URL: https://doi.org/10.2173/bow.norcar.01

Halupka, K. 1998. Partial nest predation in an altricial bird selects for the accelerated development of young. Avian Biology 29:129-133. https://doi.org/10.2307/3677190

Hannon, S. J., S. Wilson, and C. A. McCallum. 2009. Does cowbird parasitism increase predation risk to American Redstart nests? Oikos 118:1035-1043. https://doi.org/10.1111/ j.1600-0706.2008.17383.x

Heltzel, J. M., and S. L. Earnst. 2006. Factors influencing nest success of songbirds in aspen and willow riparian areas in the Great Basin. The Condor 108:842-855. https://doi.org/10.1093/ condor/108.4.842

Holway, D. 1991. Nest-site selection and the importance of nest concealment in the Black-Throated Blue Warbler. The Condor 93:575-581. https://doi.org/10.2307/1368189

Hunter, W. C., D. N. Pashley, and R. E. F. Escano. 1993. Neotropical migratory landbird species and their habitat of special concern within the Southeast Region. Pages 159-171 in D. M. Finch, and S. W. Stangel, editors. Status and management of 
neotropical migratory birds. U.S. https://doi.org/10.2737/rmgtr-229

Ibáñez-Álamo, J. D., O. Sanllorente, and M. Soler. 2012. The impact of researcher disturbance on nest predation rates: a metaanalysis. Ibis 154:5-14. https://doi.org/10.1111/j.1474-919x.2011.01186. $\mathrm{x}$

Ibáñez-Álamo, J. D., R. D. Magrath, J. C. Oteyza, A. D. Chalfoun, T. M. Haff, K. A. Schmidt, ... and T. E. Martin. 2015. Nest predation research: recent findings and future perspectives. Journal of Ornithology 156:247-262. https://doi.org/10.1007/ s10336-015-1207-4

Jongsomjit, D., S. L. Jones, T. Gardali, G. R. Geupel, and P. J. Gouse. 2007. A guide to nestling development and aging in altricial passerines. U.S. Department of Interior, Fish and Wildlife Service, Biological Technical Publication, FWS/BTPR6008-2007, Washington, D.C., USA.

King, S. L., J. P. Shephard, K. Ouchley, J. A. Neal, and K. Ouchley. 2005. Bottomland hardwood forests: past, present, and future. Pages 1-17 in L. H. Fredrickson, S. L. King, and R. M. Kaminski, editors. Ecology and management of bottomland hardwood systems: the state of our understanding. University of MissouriColumbia. Gaylord Memorial Laboratory Special Publication 10, Puxico, USA.

Knutson, M. G., B. R. Gray, and M. S. Meier. 2007. Comparing the effects of local, landscape, and temporal factors on forest bird nest survival using logistic-exposure models. Studies in Avian Biology 34:105-116.

Liebezeit, J. R., and T. L. George. 2002. Nest predators, nest-site selection, and nesting success of the Dusky Flycatcher in a managed ponderosa pine forest. The Condor 104:507-517. https:// doi.org/10.1093/condor/104.3.507

Lowther, P. E. 2020. Brown-headed Cowbird (Molothrus ater), version 1.0. In Birds of the World (A. F. Poole and F. B. Gill, Editors). Cornell Lab of Ornithology, Ithaca, NY, USA. [online] URL: https://doi.org/10.2173/bow.bnhcow.01

Lyons, T. P., J. R. Miller, D. M. Debinski, and D. M. Engle. 2015. Predator identity influences the effect of habitat management on nest predation. Ecological Applications 25:1596-1605. https:// doi.org/10.1890/14-1641.1

Martin, T. E. 1992. Breeding productivity considerations: what are the appropriate habitat features for management? Pages 455-473 in J. M. Hagan, III, and D. W. Johnston, editors. Ecology and conservation of neotropical migrant landbirds. Smithsonian Institution Press, Washington, D.C., USA.

Martin, T. E. 1993. Nest predation and nest sites: new perspectives on old patterns. BioScience 43:523-532. https://doi.org/10.2307/1311947

Martin, T. E., and J. J. Roper. 1988. Nest predation and nest-site selection of a western population of the Hermit Thrush. The Condor 90:51-57. https://doi.org/10.2307/1368432

Martin, T. E., C. R. Paine, C. J. Conway, W. M. Hochachka, P. Allen, and W. Jenkins. 1997. BBIRD field protocol. Montana Cooperative Wildlife Research Unit, University of Montana, Missoula, MT, 59812.
McDonald, M. V. 2020. Kentucky Warbler (Geothlypis formosa), version 1.0. In Birds of the World (A. F. Poole, Editor). Cornell Lab of Ornithology, Ithaca, NY, USA. [online] URL: https://doi. org/10.2173/bow.kenwar.01

Newton, I. 1998. Population Limitation in Birds. Academic Press, New York, NY, USA.

Northrup, J. M., J. W. Rivers, Z. Yang, and M. G. Betts. 2019. Synergistic effects of climate and land-use change influence broad-scale avian population declines. Global Change Biology 25:1561-1575. https://doi.org/10.1111/gcb.14571

Nudds, T. D. 1977. Quantifying the vegetative structure of wildlife cover. Wildlife Society Bulletin 25:610-611.

Payne, R. B. 2020. Indigo Bunting (Passerina cyanea), version 1.0. In Birds of the World (A. F. Poole, Editor). Cornell Lab of Ornithology, Ithaca, NY, USA. [online] URL: https://doi. org/10.2173/bow.indbun.01

Pietz, P. J., and D. A. Granfors. 2000. Identifying predators and fates of grassland passerine nests using miniature video cameras. Journal of Wildlife Management 64:71-87. https://doi. org/10.2307/3802976

Pietz, P. J., D. A. Granfors, and C. A. Ribic. 2012. Knowledge gained from video-monitoring grassland passerine nests. Pp. 3-22 in C. A. Ribic, F. R. Thompson III, and P. J. Pietz, editors. Video surveillance of nesting birds. Studies in Avian Biology (no. 43), University of California Press, Berkeley, CA, USA. https://doi. org/10.1525/california/9780520273139.003.0001

R Core Team (2019). R: A language and environment for statistical computing. R Foundation for Statistical Computing, Vienna, Austria. ISBN 3-900051-07-0, [online] URL: http://www. R-project.org/

Reidy, J. L., and F. R. Thompson III. 2012. Predatory identity can explain nest predation patterns. Pp. $135-148$ in C. A. Ribic, F. R. Thompson III, and P. J. Pietz, editors. Video surveillance of nesting birds. Studies in Avian Biology (no. 43), University of California Press, Berkeley, CA, USA. https://doi.org/10.1525/ california/9780520273139.003.0011

Reidy, J. L., and F. R. Thompson. 2018. Songbird nest survival in managed oak savannas and woodlands in the Missouri Ozarks. American Midland Naturalist 180:189-207. https://doi. org/10.1674/0003-0031-180.2.189

Remeš, V. and T. E. Martin. 2002. Environmental influences on the evolution of growth and developmental rates in passerines. Evolution 56:2505-2518. https://doi.org/10.1554/0014-3820(2002) 056[2505:eioteo]2.0.co;2

Richardson, T. W., T. Gardali, and S. H. Jenkins. 2009. Review and meta-analysis of camera effects on avian nest success. Journal of Wildlife Management 73:287-293. https://doi.org/10.2193/2007-566

Ricklefs, R. E. 1969. An analysis of nesting mortality in birds. Smithsonian Contributions to Zoology:1-48. https://doi. org/10.5479/si.00810282.9

Roach, M. C., F. R. Thompson III, and T. Jones-Farrand. 2018. Songbird nest success is positively related to restoration of pineoak savanna and woodland in the Ozark Highlands, Missouri, 
USA. The Condor: Ornithological Applications 120:543-556. https://doi.org/10.1650/condor-17-189.1

Robbins, S. K., and D. S. Wilcove. 1994. Forest fragmentation in the temperate zone and its effects on migratory songbirds. Bird Conservation International 4:233-249. https://doi.org/10.1017/ s0959270900002793

Rosenberg, K. V., A. M. Dokter, P. J. Blancher, J. R. Sauer, A. C. Smith, P. A. Smith, and P. P. Marra. 2019. Decline of the North American avifauna. Science 366:120-124. https://doi.org/10.1126/ science.aaw1313

Scott, D. M., P. J. Weatherhead, and C. D. Ankney. 1992. Eggeating by female Brown-headed Cowbirds. The Condor 94:579-584. https://doi.org/10.2307/1369242

Şekercioğlu, C. H., G. C. Daily, and P. R. Ehrlich. 2004. Ecosystem consequences of bird declines. Proceedings of the National Academy of Sciences of the United States of America 101:18042-18047. https://doi.org/10.1073/pnas.0408049101

Shaffer, T. 2004. A unified approach to analyzing nest success. The Auk 121:526-540. https://doi.org/10.1642/0004-8038(2004) 121[0526:auatan]2.0.co;2

Sharp, B. L., and B. E. Kus. 2006. Factors influencing the incidence of cowbird parasitism of Least Bell's Vireos. Journal of Wildlife Management 70:682-690. https://doi.org/10.2193/0022-541x (2006)70[682:fitioc]2.0.co;2

Sperry, J. H., G. Blouin-Demers, G. L. Carfagno, and P. J. Weatherhead. 2010. Latitudinal variation in seasonal activity and mortality in ratsnakes (Elaphe obsoleta). Ecology 91:1860-1866. https://doi.org/10.1890/09-1154.1

Stake, M. M., J. Faaborg, and F. R. Thompson III. 2004. Video identification of predators at Golden-cheeked Warbler nests. Journal of Field Ornithology 75:337-344. https://doi. org/10.1648/0273-8570-75.4.337

Stake, M. M., F. R. Thompson III, J. Faaborg, and D. E. Burhans. 2005. Patterns of snake predation at songbird nests in Missouri and Texas. Journal of Herpetology 39:215-222. https://doi. org/10.1670/150-04a

Stanton, R. L., C. A. Morrissey, and R. G. Clark. 2018. Analysis of trends and agricultural drivers of farmland bird declines in North America: A review. Agriculture, Ecosystems \& Environment 254:244-254. https://doi.org/10.1016/j.agee.2017.11.028

Streby, H. M., and D. E. Andersen. 2013. Movements, cover-type selection, and survival of fledgling Ovenbirds in managed deciduous and mixed coniferous-deciduous forests. Forest Ecology and Management 287:9-16. https://doi.org/10.1016/j. foreco.2012.08.046
Thompson III, F. R., and C. A. Ribic. 2012. Conservation implications when the nest predators are known. Pp. 23-34 in C. A. Ribic, F. R. Thompson III, and P. J. Pietz, editors. Video surveillance of nesting birds. Studies in Avian Biology (no. 43), University of California Press, Berkeley, CA, USA. https://doi. org/10.1525/california/9780520273139.003.0002

Twedt, D. J., and C. R. Loesch. 1999. Forest area and distribution in the Mississippi alluvial valley: implications for breeding bird conservation. Journal of Biogeography 26:1215-1224. https://doi. org/10.1046/j.1365-2699.1999.00348.x

Twedt, D. J., R. R. Wilson, J. L. Henne-Kerr, and R. B. Hamilton. 2001. Nest survival of forest birds in the Mississippi Alluvial Valley. Journal of Wildlife Management 65:450-460. https://doi. org/10.2307/3803097

Venables, W. N., and B. D. Ripley. 2002. Modern Applied Statistics with S. Fourth Edition. Springer, New York. ISBN 0-387-95457-0 [online] URL: http://www.stats.ox.ac.uk/pub/MASS4

Vergara, P. M., and J. A. Simonetti. 2004. Does nest-site cover reduce nest predation for Rhinocryptids? Journal of Field Ornithology 75:188-191. https://doi.org/10.1648/0273-8570-75.2.188

Weatherhead, P. J., and G. Blouin-Demers. 2003. Seasonal and prey-size dietary patterns of Black Ratsnakes (Elaphe obsoleta obsoleta). American Midland Naturalist 150:275-281. https:// doi.org/10.1674/0003-0031(2003)150[0275:sapdpo]2.0.co;2

Wilson, R. R., and R. J. Cooper. 1998. Breeding biology of Acadian Flycatchers in a bottomland hardwood forest. Wilson Bulletin 110:226-232.

Wood, D. R., and E. K. Bollinger. 1997. Egg removal by Brownheaded Cowbirds: a field test of the host incubation efficiency hypothesis. The Condor 99:851-857. https://doi.org/10.2307/1370134

Wynia, A. L., and J. C. Bednarz. 2021. Evidence of nest material kleptoparasitism in Worm-eating Warblers (Helmitheros vermivorum) in East-central Arkansas. Ecology and Evolution 00:1- 5. https://doi.org/10.5061/dryad.q573n5thc
Editor-in-Chief: Alexander L.Bond Subject Editor: Erin Bayne
Sponsored by the Society of Canadian Ornithologists and Birds Canada

Parrainée par la Société des ornithologistes du Canada et Oiseaux Canada

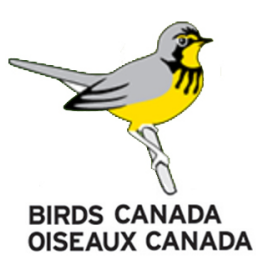

